\title{
Complexity and education: Inquiries into learning, teaching and research
}

Brent Davis \& Dennis Sumara, 2006

Mahwah, New Jersey \& London, Lawrence Erlbaum Associates

\$19.95 USD (pbk), 202pp.

ISBN 0-8058-5953-7

Foundational articles on complexity theory were published almost sixty years ago but received little attention outside of science. In the last thirty years, interest in complexity theories has grown dramatically, and inquiries into complexity have evolved into a multidisciplinary body of complexity science. In Complexity and Education:

Inquiries into Learning, Teaching and Research, Davis and Sumara make a significant contribution to complexity's continued evolution.

Though rooted in scientific inquiry, insights from complexity theory and science are increasingly being applied to areas within the social sciences and humanities. Of the plethora of articles and books that utilize complexivist insights, relatively few focus on applications in the domain of education. For the majority of educationists complexity is an unfamiliar concept, however, growing recognition of its relevance to education is signaling a shift in the way we might conceptualize and enact teaching and learning. Recently, understandings from complexity have been applied to a number of areas in education, including curriculum, leadership, teacher education and research design, to name only a few. Davis and Sumara forward an original transdisciplinary exploratory discourse on complexity thinking and educational practice and inquiry. In Complexity and Education, complexity is viewed as neither a single coherent 'theory' nor a new discipline within the tradition of 'science' but as a radically new way of thinking.

As complexity is a dynamic, evolving area of inquiry and understanding, providing an exact, static, universal definition of it proves difficult. For the same reasons, the authors readily acknowledge the futility of any effort to provide a comprehensive, prescriptive account of complexity and education. Complexity thinking is not a metadiscourse but a broad notion that facilitates the recognition of profound similarities among a wide array of phenomena. Inquiries motivated by complexivist sensibilities take a variety of non-linear (i.e. complex) systems as their subject matter (e.g. climactic, economic, biological and social systems). As envisioned by Davis and Sumara, complexity thinking constitutes a new direction of inquiry and analysis that departs from traditional linear-reductionist analyses and offers effective alternatives to experimental and quantitative research methodologies.

A key concept in the authors' theorization of complexity and education is based on the observation that all complex systems learn. For Davis and Sumara, a learner is "a complex unity that is capable of adapting itself to the sorts of new and diverse circumstances that an active agent is likely to encounter in a dynamic world" (p. 14). This broad description allows other complex unities (such as cells and cultures) to also be viewed as learners, an insight that is prompting a shift in the conceptualization of learning from a process of Newtonian mechanics to one of Darwinian dynamics. The strength of this assertion lies in the natural fit of complexity thinking to educational discourse.

Journal of Contemporary Issues in Education, 2006, 1(1), pp.54-55

ISSN 1718-4770 C 2006 University of Alberta

http://ojs.educ.ualberta.ca/index.php/jcie/ 
The book is presented in two parts, each containing four chapters. In part one, the authors address general issues around complexity thinking by considering the questions 'What is complexity?' (Chapter one) and 'What is science?' (Chapter two). These chapters outline reasons for the authors' choice of the term 'complexity thinking' over the more common 'complexity theory' or 'complexity science'. Chapter three draws on geometry, etymology, fractals and networks in considering 'The Shape of Complexity', while Chapter four traces the evolution of complexity thinking within educational discourses. The organizational structure and narrative style of these chapters provide an excellent introduction to complexity thinking for readers new to its concepts.

In part two, the authors present a broad array of practices and studies informed by complexity thinking that are being undertaken in education. Chapters five and six focus on the development of descriptive principles used to identify complex systems as well as their practical application in educational environments (with a series of useful examples drawn from a collaborative research project in which the authors were involved). The final chapters provide pragmatic advice for educational practitioners and researchers seeking to affect, rather than simply describe, phenomena of interest. According to Davis and Sumara, this involves an understanding of the conditions that lead to the emergence of complex systems as well as attention to events that occur simultaneously at multiple levels of complex activity. The use of practical examples throughout these chapters strengthens the authors' presentation of complexity thinking as a valuable and appropriate attitude for both teachers and researchers.

The book is written in clear and engaging prose, yet poses numerous conceptual and theoretical challenges to deeply held assumptions and theories about teaching and learning. Some readers may have difficulty with the broad range of theories and perspectives the authors draw on throughout the text (e.g. phenomenology, hermeneutics, post-structuralism, psychoanalysis and neurology). The broad scope of the book, however, is also evidence of the transdisciplinary nature of complexity thinking; there is truly something in this book for almost everyone. The authors use many examples to ground their theoretical insights in classroom practice, and develop relevant vocabulary (e.g. fractals, scale-free networks, self-organization, bottom-up and nested organization), establishing a degree of clarity around applications of complexity thinking in education. Their description and analysis of self-organizing, nested learning systems (e.g. brains, social collectives and bodies of knowledge) is an exciting, even revolutionary with respect to this emergent realm of inquiry. Complexity and Education is an important summary of insights gleaned from complexity thinking that question the assumptions of more traditional approaches to education. Davis and Sumara have produced a remarkable account of the transformative possibilities inherent in the application of complexity thinking to educational practice and inquiry. This work is suitable for teachers, academics and graduate students interested in crossing disciplinary boundaries and exploring new possibilities in education.

Jeff J. Baker

University of Alberta 